\title{
Politique
}

\section{Index des notes de recherche publiées en 1989}

Numéro 16, automne 1989

Les États-Unis

URI : https://id.erudit.org/iderudit/040644ar

DOI : https://doi.org/10.7202/040644ar

Aller au sommaire du numéro

Éditeur(s)

Société québécoise de science politique

ISSN

0711-608X (imprimé)

1918-6584 (numérique)

Découvrir la revue

Citer ce document

(1989). Index des notes de recherche publiées en 1989. Politique, (16), 155-156.

https://doi.org/10.7202/040644ar

Ce document est protégé par la loi sur le droit d'auteur. L’utilisation des services d'Érudit (y compris la reproduction) est assujettie à sa politique d'utilisation que vous pouvez consulter en ligne.

https://apropos.erudit.org/fr/usagers/politique-dutilisation/
Cet article est diffusé et préservé par Érudit.

Érudit est un consortium interuniversitaire sans but lucratif composé de l’Université de Montréal, l’Université Laval et l'Université du Québec à Montréal. Il a pour mission la promotion et la valorisation de la recherche. https://www.erudit.org/fr/ 


\section{Index des notes de recherche publiées en 1989}

BRUNELLE, Dorval, DEBLOCK, Christian et HECTOR, Cary (sous la direction de) Le Canada et le Mexique: autonomie et interdépendance dans les années 1980, Montréal, Université du Québec à Montréal, Département de science politique, mai 1989.

CARRIER, Luc, L'institutionnalisation de l'Assemblée nationale du Québec: une étude diachronique de la professionnalisation du personnel politique québécois, 1867-1987, Québec, Université Laval, Département de science politique, janvier 1989.

FOURNIER, Bemard, Mouvements de jeunes et socialisation politique: la dynamique de la JEC a l'époque de Gérard Pelletier, Québec, Université Laval, Département de science politique, janvier 1989

GONGORA, T., Les armes de Qadhafi: politique étrangère et planification militaire en Libye, Montréal, Université de Montréal, Département de science politique, 1989.

LAFOREST, Guy, Normalisation et sciences humaines, Québec, Université Laval, Département de science politique, février 1989.

LEMIEUX, Vincent, La science politique selon Jean Meynaud: quelques réflexions toujours actuelles, Québec, Université Laval, Département de science politique, avril 1989. 
LEMIEUX, Vincent, Les politiques publiques et l'exercice du pouvoir, (2e éd. revue et corrigée), Québec, Université Laval, Département de science politique, juin 1989. 